\title{
HUBUNGAN AKTIVITAS FISIK LANSIA DENGAN KEPADATAN TULANG DI POSKESKEL RENGAS PULAU MARELAN MEDAN
}

\author{
Relationship Physical Activity With Elderly Density Bone \\ In Poskeskel Rengas Pulau Marelan Medan
}

\author{
Rosalina Imelda Sembiring \\ Dosen Tetap Yayasan Akper Kesdam I/BB Medan \\ email : rosalina.depari@gmail.com
}

\begin{abstract}
Abstrak
Hubungan aktivitas fisik lansia dengan kepadatan tulang di Poskeskel Rengas Pulau Marelan Medan Tahun 2014. Proporsi penduduk lansia Indonesia tahun 2000 adalah 7,18\%, tahun 2010 meningkatkan sekitar 9,7\%, sedangkan tahun 2020 diperkirakan meningkatkan sekitar 11,34\% (BKKBN, 2012). Proses penuaan tidak dapat dihentikan, namun dapat diperlambat. Transisi demografi kearah menua tidak dapat dihentikan, namun dapat diperlambat. Transisi demografi kearah menua akan diikuti oleh transisi epidemiologi kearah penyakit degeneratif yang salah satunya adalah osteoporosis. Prevalensi osteoporosis di Jakarta, Surabaya, Semarang, Bandung dan Medan penderita osteoporosis sudah mencapai 30\% (Hans, 2009). Tujuan penelitian ini adalah mengetahui hubungan aktivitas fisik dengan kepadatan tulang lansia.

Jenis penelitian adalah survey potong lintang (cross sectional survey). Populasi adalah kelompok lansia di Poskeskel Rengas Pulau Marelan Medan sebanyak 83 orang dibantu dengan menggunakan alat ukur bone densitometry portable (metode ultrasound) yang dibantu tim Anlene. Uji yang digunakan adalah uji Chi-Square dan uji Regresi Logistik Ganda.

Hasil penelitian di Poskestel Rengas Pulau Marelan Medan Tahun 2014, lansia yang menderita osteoporosis sebanyak $27,7 \%$. Intensitas latihan berhubungan dengan kepadatan tulang setelah dikontrol oleh usia, kebiasaan merokok, dan kebiasaan minum kopi. Lansia dengan intensitas latihannya kurang lama beresiko terjadi osteoporosis 52 kali dibanding dengan lansia yang intensitas latihannya lama. Bagi Pemerintah memberikan alat Bone Densito Metri Portable di setiap puskesmas kecamatan untuk screening osteoporosis yang dijadikan riset Nasional. Bagi Poskeskel Rengas Pulau Marelan Medan, meningkatkan pelayanan kesehatan dan penyuluhan pada lansia, khususnya penyuluhan tentang aktifitas fisik lansia. Bagi Responden, agar dapat mempertahankan kegiatan sehari-hari dan tetap aktif dalam kegiatan kelompok lansia yang ada di poskeskel Rengas Pulau Marelan Medan, sehingga dapat mempertahankan kualitas kepadatan tulang yang baik dan meningkatkan kualitas kepadatan tulang yang sudah osteoporosis.
\end{abstract}

Kata kunci : Osteoporosis, umur, kebiasaan merokok, kebiasaan minum kopi

\section{Pendahuluan}

Latar Belakang

Lanjut usia (Lansia) adalah seseorang yang telah mencapai usia 60 tahun ke atas. Keadaan ini dibagi menjadi dua, yaitu lansia potensial dan lansia tidak potensial. Lansia potensial adalah lansia yang masih mampu melakukan pekerjaan dan atau kegiatan yang dapat menghasilkan barang dan jasa, sedangkan lansia tidak potensial adalah lansia yang tidak berdaya mencari nafkah sehingga hidupnya begantung pada bantuan orang lain (Komnas Lansia, 2010).

Undang-undang Kesehatan nomor 36 tahun 2009 menyebutkan bahwa upaya untuk meningkatkan dan memelihara kesehatan masya- rakat termasuk lansia dilaksanakan berdasarkan prinsip non diskriminatif, partisipatif dan berkelanjutan. Setiap upaya untuk meningkatkan derajat kesehatan masyarakat merupakan investasi bagi pembangunan Negara. Prinsip non diskriminatif mengandung makna bahwa semua masyarakat harus mendapatkan pelayanan kesehatan termasuk lansia (Komnas Lansia, 2010).

Penggolongan lansia menurut WHO meliputi : middle age (45 - 49 tahun), elderly (60-74 tahun), old (75-79 tahun), very old (diatas 90 tahun). Menurut UU No. 13 tahun 1998 Pasal 1 ayat 2 tentang kesejahteraan Lanjut usia (lansia) menyatakan bahwa lanjut usia adalah seseorang yang telah mencapai usia 60 tahun ke atas. Pada tahun 2000, penduduk usia lanjut di seluruh dunia diperkirakan sebanyak 426 juta atau sekitar 6,8\%. Jumlah ini akan meningkat hampir dua kali lipat 
pada tahun 2025, yaitu menjadi sekitar 828 juta jiwa atau sekitar $9,7 \%$ dari total penduduk dunia. Dinegara-negara maju, jumlah lansia juga mengalami peningkatan, antara lain : Jepang $(17,2 \%)$, Singapura $(8,7 \%)$, Hongkong $(12,9 \%)$, dan Korea Selatan (7,5\%) sudah cukup besar sejak dekade 1990-an. Sementara Negara-negara seperti Belanda, Jerman, dan Perancis sudah lebih dulu menghadapi masalah yang serupa (Nugroho, 2012).

Proses penuaan tidak dapat dihentikan, namun dapat diperlambat. Berdasarkan bukti ilmiah terdapat beberapa kegiatan simulasi otak yang bermanfaat, seperti aktifitas fisik, stimulasi mental, dan aktivitas sosial. Terbukti bahwa kombinasi ketiganya lebih bermanfaat untuk menstimulasi otak dan meningkatkan kualitas hidup lansia dibandingkan secara tersendiri. Peranan fasilitator sangat besar pada kelangsungan kegiatan kelompok lansia di komunitas, sehingga perlu dilakukan pelatihan fasilitator agar dapat berkomunikasi dengan lansia secara efektif dan kegiatan berjalan lancar (Alissa, 2009).

Pada umumnya, gerak badan dan aktivitas fisik menurun secara signifikan dalam jangka panjang dengan meningkatnya penuaan seseorang. Peningkatan aktivitas fisik menurunkan resiko kegemukan, diabetes tipe II, tekanan darah tinggi dan penyakit jantung, osteoporosis, osteoarthritis, beberapa jenis kanker, dan depresi. Aktivitas juga dapat memperbaiki kualitas hidup seseorang melalui peningkatan kebugaran dan perbaikan rasa sehat (Julia, 2011).

Osteoporosis menyebabkan lebih dari 8,9 juta penduduk dunia patah tulang setiap tahunnya, mengakibatkan fraktur osteoporosis setiap 3 detik. Osteoporosis diperkirakan mempengaruhi 200 juta wanita di seluruh dunia sekitar sepersepuluh dari wanita berusia 60 , seperlima dari wanita usia 70, dua-perlima dari wanita berusia 80 dan dua-pertiga dari perempuan berusia 90. Osteoporosis mempengaruhi sekitar 7 juta orang di Eropa, Amerika Serikat dan Jepang. Untuk tahun 2000, diperkirakan ada 9 juta patah tulang osteoporosis baru, yang 1,6 jua berada di pinggul, 1,7 juta berada di lengan bawah dan 1,4 juta adalah patah tulang ini, sementara sebagian besar sisanya terjadi wilayah Pasifik Barat dan Asia Tenggara (IOF, 2014).

Bila dilihat perkembangannya, derajat kesehatan penduduk lansia relatif tidak berbeda. Angka kesakitan penduduk lansia pada tahun 2005 sebesar 29,98\%, tahun 2007 sebesar 31,11\% dan tahun 2009 sebesar 30,46\%. Pola yang serupa terjadi baik di perkotaan maupun di pedesaan. Kebiasaan berobat serta cara berobat yang dilakukan seseorang, merupakan salah satu faktor yang digunakan untuk mengidentifikasi apakah orang yang bersangkutan telah memiliki perilaku hidup sehat. Berdasarkan Profil Penduduk Lansia 2009 , ternyata $32,24 \%$ lansia mencari pengobatan di Puskesmas, namun masih ada yang mengobati sendiri dengan menggunakan obat modern $60,47 \%$ dan obat tradisional $10,87 \%$ (Kepmenkes, 2013).

Kini terdapat dua ratus juta penderita osteoporosis di seluruh dunia, satu diantara tiga wanita dan satu di antara lima pria di atas 50 tahun adalah penderita osteoporosis. Prediksi 2050 diperkirakan akan ada 6,3 juta patah tulang panggul setiap tahun diseluruh dunia, yang lebih dari setengahnya terdapat di Asia. Jumlah penderita osteoporosis di Indonesia jauh lebih besar dari data terakhir Depkes. Di Jakarta, Surabaya, Semarang, Bandung, dan Medan penderita osteoporosis sudah mencapai $30 \%$ (Hans, 2009).

Berdasarkan survey awal peneliti di posyandu lansia di Poskeskel Rengas Pulau Marelan Medan bahwa ada sekitar 200 orang kurang lebih lansia yang terdaftar. Lansia yang datang ke posyandu dengan keluhan asam urat, rematik dan tekanan darah tinggi. Aktifitas fisik seperti senam dilakukan satu kali dalam seminggu.

\section{Metode Penelitian Desain Penelitian}

Desain penelitian yang akan digunakan dalam penelitian ini adalah pendekatan kuantitatif dengan desain Cross sectional (Penelitian yang dilakukan hanya sekali saja) yakni bertujuan untuk mengetahui hubungan aktivitas fisik lansia dengan kepadatan tulang di Poskeskel Rengas Pulau Marelan.

Sampel adalah sebagian dari populasi. Besarnya sampel dalam peneliti adalah dengan menggunakan rumus estimasi proporsi populasi dengan presisi mutlak (Ariawan, 1998) sebagai berikut $: n=\frac{Z^{2} 1-\alpha / 2 . P(1-P)}{d^{2}}$

Lokasi penelitian ini dilakukan di Poskeskel Rengas Pulau Marelan Medan dengan alasan karena lokasi penelitian dekat dengan rumah peneliti sehingga akan memudahkan peneliti dalam pengumpulan data.

Jenis data yang dikumpulkan pada penelitian ini meliputi data sekunder dan data primer. Data primer meliputi umur, pendidikan, jenis kelamin, latihan fisik, intensitas latihan, 
kebiasaan konsumsi kopi, kebiasaan konsumsi alkohol, kebiasaan mengkonsumsi obat-obat steroid, dan kebiasaan merokok, diperoleh dengan wawancara langsung dengan pengisian kuesioner. Sedangkan data kepadatan tulang diperoleh dari Bone Densitometry Portable (metode ultrasound) (Misnadiarly, 2013).

\section{Hasil}

Analisis univariat dilakukan untuk mengetahui kepadatan tulang lansia, umur, pendidikan, jenis kelamin, latihan fisik, insensitas latihan, kebiasaan konsumsi kopi, kebiasaan konsumsi alkohol, kebiasaan konsumsi obatobatan steroid, dan kebiasaan merokok di Poskeskel Rengas Pulau Marelan Medan tahun 2014.

Distribusi Responden Menurut Kepadatan Tulang di Poskeskel Rengas Pulau Marelan Medan

\begin{tabular}{llll}
\hline \multicolumn{2}{l}{ Kepadatan Tulang } & n & $\%$ \\
\hline Normal & 60 & 72,3 & \\
Osteoporosis & & 23 & 27,7 \\
Total & 83 & 100 \\
\hline
\end{tabular}

Dapat dilihat bahwa dari 83 responden kepadatan tulang normal sebanyak 60 orang $(72,3 \%)$, selebihnya osteoporosis sebanyak 23 orang $(27,7 \%)$.

Distribusi Responden Menurut Umur di Poskeskel Rengas Pulau Marelan Medan

\begin{tabular}{lll}
\hline Umur & n & $\%$ \\
\hline $\begin{array}{l}\text { Lansia (60-69 tahun) } \\
\text { Lansia Tua (> 70 18 }\end{array}$ & 65 & 78,3 \\
$\begin{array}{l}\text { tahun) } \\
\text { Total }\end{array}$ & 83 & 100 \\
\hline
\end{tabular}

Dapat dilihat bahwa dari 83 responden yang berumur lansia (umur 60-69 tahun) sebanyak 65 orang $(78,3 \%)$, selebihnya berumur lansia tua yaitu sebanyak 18 orang $(21,7 \%)$.

Distribusi Responden Menurut Pendidikan di Poskeskel Rengas Pulau Marelan Medan

\begin{tabular}{lll}
\hline Pendidikan & n & $\%$ \\
\hline > SMP 16 & & 19,3
\end{tabular}

$\leq$ SMP 67

Total 83

80,7 100

Dapat dilihat bahwa dari 83 responden yang berpendidikan > SMP yaitu sebanyak 16 orang (19,3\%), selebihnya berpendidikan $\leq$ SMP yaitu sebanyak 67 orang $(80,7 \%)$.

Distribusi Responden Menurut Jenis Kelamin di Poskeskel Rengas Pulau Marelan Medan

\begin{tabular}{lll}
\hline Umur & $\mathbf{n}$ & $\boldsymbol{\%}$ \\
\hline Laki-laki & 8 & 9,6 \\
Perempuan & 75 & 90,4 \\
Total & 83 & 100 \\
\hline
\end{tabular}

Dapat dilihat bahwa dari 83 responden yang berjenis kelamin perempuan sebanyak 75 orang $(90,4 \%)$, selebihnya jenis kelamin laki-laki yaitu sebanyak 8 orang $(9,6 \%)$.

\section{Hasil Seleksi Bivariat}

\begin{tabular}{ll}
\hline Variabel & P value \\
Umur & 0,242 \\
Jenis kelamin & 0,159 \\
Intensitas latihan & 0,001 \\
Kebiasaan Konsumsi Kopi 0,013 & \\
Kebiasaan Konsumsi Obat & 0,081 \\
Steroid & \\
Kebiasaan merokok & 0,030 \\
\hline
\end{tabular}

Hasil seleksi bivariat adalah variable umur, jenis kelamin, intensitas latihan, kebiasaan konsumsi kopi, kebiasaan konsumsi obat-obatan steroid, dan kebiasaan merokok menghasilkan $\mathrm{p}$ value $<0,25$ yang artinya variable independen tersebut menjadi kandidat untuk analisis multivariate.

\section{Pemodelan Multivariat}

\begin{tabular}{lll}
\hline Variabel & P value OR & \\
\hline Usia & 0,657 & 0,697 \\
Jenis kelamin & 0,824 & 1,290 \\
$\begin{array}{l}\text { Intensitas } \\
\text { latihan }\end{array}$ & 0,001 & 49,755 \\
$\begin{array}{l}\text { Kebiasaan } \\
\text { merokok }\end{array}$ & 0,622 & 1,944 \\
$\begin{array}{l}\text { Kebiasaan } \\
\text { Konsumsi kopi }\end{array}$ & 0,072 & 0,193 \\
$\begin{array}{l}\text { Kebiasaan } \\
\text { Konsumsi obat steroid }\end{array}$ & 0,811 & 0,823
\end{tabular}


Variabel yang terbesar $p$ value nya adalah jenis kelamin, dengan demikian dikeluarkan dari model dan hasilnya sebagai berikut:

\section{Pemodelan Multivariat Tanpa Variabel Jenis Kelamin}

\begin{tabular}{lll}
\hline Variabel & $\begin{array}{l}\text { P value } \\
\text { Sebelum }\end{array}$ & OR \\
Sebelum Sesudah Sesudah
\end{tabular}

\begin{tabular}{|c|c|c|c|c|}
\hline Usia & 0,657 & 0,697 & 0,643 & 0,686 \\
\hline $\begin{array}{l}\text { Intensitas } \\
\text { Latihan }\end{array}$ & 0,001 & 49,755 & 0,001 & 48,894 \\
\hline $\begin{array}{l}\text { Kebiasaan } \\
\text { Merokok }\end{array}$ & 0,622 & 1,944 & 0,525 & 2,193 \\
\hline $\begin{array}{l}\text { Kebiasaan } \\
\text { Konsumsi }\end{array}$ & $\begin{array}{l}0,072 \\
\text { kopi }\end{array}$ & 0,193 & 0,074 & 0,196 \\
\hline $\begin{array}{l}\text { Kebiasaan } \\
\text { Obat-obata }\end{array}$ & $\begin{array}{c}0,811 \\
\text { n steroid }\end{array}$ & 0,823 & 0,803 & 0,816 \\
\hline
\end{tabular}

Setelah variabel jenis kelamin dikeluarkan, akan terjadi perubahan OR ternyata ada perubahan OR < $10 \%$ pada variabel umur, intensitas latihan, kebiasaan merokok, kebiasaan konsumsi kopi, dan kebiasaan konsumsi obat steroid. Dengan demikian variabel jenis kelamin tetap dikeluarkan dari model dan varibel kebiasaan konsumsi obat-obatan steroid dikeluarkan karena $\mathrm{p}$ value nya terbesar dan hasilnya sebagai berikut:

Model Terakhir Dari Permodelan Multivariat

\begin{tabular}{lcc}
\hline Variabel & Pvalue & OR \\
\hline Intensitas Latihan & 0,001 & 52,070 \\
Usia & 0,645 & 0,688 \\
Kebiasaan merokok & 0,491 & 2,315 \\
Kebiasaan konsumsi & 0,066 & 0,190 \\
kopi & & \\
\hline
\end{tabular}

Dari tabel dapat kita lihat bahwa berdasarkan analisis multivariate variabel yang berhubungan dengan kepadatan tulang adalah intensitas latihan $(\mathrm{p}$ value $=0,001$ dan $\mathrm{OR}=$ 52,070) artinya lansia intensitas latihannya kurang lama beresiko terjadi osteoporosis 52,070 kali dari lansia yang intensitas latihannya lama. Variabel confounding antara lain: usia, kebiasaan merokok, dan kebiasaan konsumsi kopi.

\section{PEMBAHASAN}

Kejadian Osteoporosis Lansia

Osteoporosis adalah suatu keadaan dimana terdapat pengurangan jaringan tulang per unit volume, sehingga tidak mampu melindungi atau mencegah terjadinya fraktur terhadap trauma minimal. Pengurangan massa tulang tersebut tidak disertai dengan adanya perubahan perbandingan antara substansi mineral dan organik tulang secara histopatologis osteoporosis ditandai oleh berkurangnya ketebalan korteks disertai dengan berkurangnya jumlah maupun ukuran tratekula tulang. Dengan demikian tampaknya dari luar ukuran anatomis tulang tersebut dalam batas mormal (Javier, 2010).

Terdapat sedikitnya lima provinsi di Indonesia masuk kategori resiko tinggi penderita penyakit osteoporosis yaitu Sumatera Selatan, Jawa Tengah, Yogyakarta, Sumatera Utara, dan Jawa Timur. Dalam data tersebut disebutkan bahwa 27,7\% penduduk Sumatera Selatan terkena osteoporosis, Jawa Tengah (24,02\%), Yogyakarta $(23,5 \%)$, Sumatera Utara $(22,82 \%)$, Jawa Timur (21,42\%), dan Kalimantan Timur (10,5\%) (Puslitbangkes Gizi Depkes RI, 2007).

Menurut Misnadiarly (2013), olahraga beban yang teratur sangat baik untuk mencegah osteoporosis. Mulailah dengan intensitas ringan kemudian ditingkatkan hingga 30 sampai 40 menit per sesi beberapa kali dalam seminggu. Walaupun berenang tidak termasuk olahraga beban, tetapi sangat baik untuk memperkuat otot punggung. Semakin kuat otot punggung, maka semakin kuat dan padat pula tulang belakang. Olahraga air ini juga merupakan pilihan yang bagus bagi penderita radang sendi atau orang yang mengalami rasa nyeri jika melakukan olahraga beban.

Menurut Hans (2009), olahraga aerobik memperbaiki fungsi jantung dan peredaran darah, dan baik untuk penderita hipertensi atau diabetes. Contoh olahraga aerobik adalah jalan kaki, jogging, sepeda statis, berenang, atau senam. Pada jalan aerobik, tulang tungkai dan panggul bergerak teratur sedangkan kedua kaki menginjak atau menyentuh tanah secara bergantian. Apabila jalan aerobik dilakukan dengan perlahan-lahan atau intensitas ringan, hanya sedikit pengaruhnya bagi kepadatan tulang. Bila diteliti memang ditemukan bahwa jalan kaki bisa memperbaiki massa tulang panggul dan tulang belakang serta mengurangi pengeroposan, tetapi harus dilakukan dengan intensitas yang lebih keras, artinya harus jalan cepat, dengan kecepatan sampai 8-10 km per jam. Jalan perlahan-lahan atau hanya 4-6 km per jam tidak banyak gunanya untuk kepadatan tulang. Aerobik lain yang dianjurkan untuk tulang dansa, jogging, atau naik turun tangga.

Menurut Fatmah (2010), intensitas latihan adalah kerasnya kita melakukan latihan. 
Misalnya, seberapa cepat kita melakukan olahraga jalan kaki. Intensitas latihan dapat diketahui dengan menghitung denyut nadi jumlahnya meningkat bila kita melakukan olahraga/aktivitas fisik. Pada saat latihan olahraga, denyut nadi harus bisa melampui $60 \%$ dari denyut nadi maksimal (DNM) yaitu 60\% dari 220 dikurangi usia.

\section{Simpulan dan Saran Simpulan}

Kejadian Osteoporosis pada lansia di Poskeskel Rengas Pulau Medan 27,7\%, lebih tinggi disbanding dengan tingkat Nasional $(19,7 \%)$ dan tingkat Provinsi Sumatera Utara $(22,82 \%)$. Faktor yang berhubungan dengan kepadatan tulang adalah intensitas latihan ( $p$ value $=0,001$ dan $\mathrm{OR}=52,070)$ artinya lansia yang intensitas latihannya kurang lama beresiko terjadi osteoporosis 52 kali dari lansia yang intensitas latihannya lama, setelah dikontrol oleh variabel usia, kebiasaan merokok, dan kebiasaan konsumsi kopi.

\section{Saran}

Bagi Pemerintah

Memberikan alat Bone Densito Metri Portable di setiap puskesmas kecamatan untuk screening osteoporosis dijadikan riset Nasional. Bagi Poskeskel Rengas Pulau Marelan Medan

Meningkatkan pelayanan kesehatan dan penyuluhan pada lansia, khususnya penyuluhan tentang aktifitas fisik lansia.

Bagi Responden
Bagi lansia agar dapat mempertahankan kegiatan sehari-hari dan tetap aktif dalam kegiatan kelompok lansia yang ada di Poskeskel Rengas Pulau Marelan Medan, sehingga dapat mempertahankan kualitas kepadatan tulang yang baik dan meningkatkan kualitas kepadatan tulang yang sudah osteoporosis.

Bagi Peneliti

Agar dapat melanjutkan penelitian yang mendalam tentang osteoporosis dengan mengambil jumlah sampel yang lebih besar lagi agar mendapatkan hasil yang lebih akurat.

\section{Daftar Pustaka}

Arikunto, S. (2010), Penelitian Suatu Prosedur Pendekatan Praktik, Jakarta: Rineka Cipta.

Arofani Hermastuti. (2012). Hubungan Indeks Massa Tubuh, massa lemak tubuh, asupan kalsium tubuh, aktifitas fisik, dan kepadatan tulang pada wanita dewasa muda.

Ai Sri Kosyani, (2007), Hubungan Asupan Kalsium, Aktivitas Fisik, Paritas, Indeks Massa Tubuh Dan Kepadatan Tulang Pada Wanita Pascamenopause. Semarang: Universitas Diponegoro.

Javier. (2010), Kupas Tuntas Osteoporosis. Yogyakarta: Multipress

Kemenkes RI. (2011). Kecakapan Dan Pengasuhan Lansia, Jakarta. 